\title{
O ensino jurídico em contexto universitário portu- guês: tradições curriculares em debate
}

\section{Resumo}

Cely do Socorro Costa Nunes Universidade de Lisboa | Portugal

Oartigo objetiva compreender como a invenção/manutenção das tradições curriculares no ensino jurídico se estabelece em uma instituição universitária. Busca-se, a partir de 20 horas de observação de sala de aula, entrevistas à professora e a 11 estudantes e análise documental, compreender como este ensino é percepcionado pela sua comunidade. Apple (1999), Goodson (2001), Fernandez e Fernandez (2005), Hobsbawm (2008), Francishetto (20 10), Leite (20 1 1) ajudam a ponderar que tal ensino decorre de uma tradição curricular favorecedora da manutenção do Estilo Coimbrã de ensino: dicotomia teoria e prática e do conhecimento técnico e político, cuja raiz reside na vocação do Direito Positivo. Tradição pouco contestada pelo ensino jurídico lusófono, contribuindo para sua perpetuação a qual dificulta que outras tradições curriculares críticas possam ser inventadas.

Palavras-chave: Ensino jurídico. Educación superior.

\section{Law education within thecontext of Portuguese university: curricular traditions under debate}

\section{Abstract}

The goal of the article is to understand how current curricular traditions are established and maintained in legal education established in a university institution. We search, from 20 hours of observation in the classroom, interviews with the teacher and with 11 students and documentary analysis understand how the educational community perceives teaching. Apple (1 999), Goodson (2001), Fernandez and Fernandez (2005), Hobsbawm (2008), Francishetto (2010), Leite (2011) help to consider that such teaching stems from a curricular tradition favoring the maintenance of a Coimbrã style of teaching: dichotomy of theory and practice and of technical and political knowledge, based on the Positive Law. Tradition little challenged by the Portuguese-speaking legal education, contributing to its perpetuation, which makes it difficult for other curricular traditions criticism can be invented.

Keywords: Curriculum traditions. Legal education. Highereducation. 


\section{Las oportunidades para el aprendizaje y la ciudadanía responsable: las prácticas democráticas de aula}

\section{Resumen}

El artículo pretende entender cómo la invención y mantenimiento de las tradiciones curriculares en la educación legal se asientan en una institución universitaria. Búsqueda de 20 horas aula observación, entrevistas con la maestra y 11 estudiantes y análisis documental, para entender cómo esta enseñanza es percibida por su comunidad. Apple (1999), Goodson (200 1), Fernández y Fernández (2005), Hobsbawm (2008), Francishetto (2010), Leite (2011) nos ayudan a pensar que tales enseñanzas se derivan de una tradición curricular del estilo Coimbrã de enseñanza: dicotomía teoría y práctica y conocimientos técnicos y políticos, cuya raíz es la vocación de la ley positiva. Tradición poco cuestionado por la educación jurídica portuguesa, lo que contribuye a su perpetuación que hace que sea difícil para otras tradiciones curriculares puedan ser inventados.

Palabras clave: Tradiciones curriculares. Educación legal. Educación superior.

\section{Contexto do estudo}

Este artigo insere-se em um projeto de investigação' que tem como propósito conhecer e compreender processos de ensino, avaliação e aprendizagem numa variedade de cursos de universidades portuguesas e brasileiras. O problema desta investigação decorre da constatação, amplamente identificada e reconhecida na literatura de que o trabalho empírico realizado na sala de aula do ensino superior é fundamental para se conhecer e compreender, com mais pronfundidade, o desenvolvimento curricular no ensino superior. Trabalhos, como os de Leite (2010, 201 1), Fernandes e Fialho (2012); Zabalza (2011) mostraram que é possível melhorar os processos de ensino superior e, assim, aprimorar, substancialmente, o que, e como os estudantes aprendem. A importância e a natureza inovadora deste estudo decorreram da intenção de se analisar tais processos de forma indissociável umavez que estão interligados e integrados no processo de formação profissional dos estudantes. Ademais, decorrem, também, do fato de se prever uma investigação extensiva, intensiva e integrada ao contexto de uma variedade de cursos de Ciências Sociais, Artes 
ensino jurídico em contexto universitário português: tradições curriculares em debate

e Humanidades, Engenharias e Tecnologias e Ciências da Saúde. Este projeto desenvolve-se, desde abril de 2011 , e participam dele quatroUniversidades Portuguesas (Lisboa, Coimbra, Minho e Évora) e trêsbrasileiras (Universidade de São Paulo, Universidade do Estado do Pará e Universidade da Amazônia), as quais compõem o ambiente de trabalho da equipe de investigação.

A investigação referida ainda está em curso e este artigo apresenta e discute resultados em que se prioriza uma análise do processo ensino-aprendizagem do Curso de Direito de uma universidade pública portuguesa, escolhido, aleatoriamente, mediante um rol de cursos pertencentes à área das Ciências Sociais que aderiram, voluntariamente, à pesquisa. Assim, o estudo analisa o ensino jurídico desenvolvido em uma unidade curricular (disciplina) localizada no $1^{\circ}$ semestre do $3^{\circ}$ ano do referido Curso. Embora o estudo esteja centradoem uma única unidade curricular,compreende-se, como admite Goodson (2001), que ela não é uma entidade monolítica mas, antes, amálgamas flutuantes de subgrupos e de tradições que, através da contestação e do compromisso, influenciam o rumo das mudanças.Portanto, tal unidade curricular não está isolada em uma estrutura curricular; ao contrário, há, entre estes corpus, uma relação homóloga sobre a qual se implicam direta e mutuamente 14 permitindorefletir acerca da invenção/manutenção de certas tradições curriculares no ensino jurídico. Para citar outra vez Goodson (2001), tais tradições incitam o professor em visões amplamente diferentes sobre as hierarquias do conhecimento, os conteúdos, o papel dos docentes, as orientações pedagógicas globais e o sistema de relações que lhes subjazem, isto é, acrescenta o autor, o destino das tradições disciplinares está, claramente, ligado de forma estreita aos padrões de conhecimento e à pedagogia da sala de aula.

Contribuições teóricas de Eric Hobsbawm (2008, 2008a) acerca da invenção de tradições apresentam-se pertinentes para este estudo na medida em que destaca algumas sínteses conceituais. Assim, toma-se,como referência, a definição do termo tradições que, como pondera Hobsbawm (2008), podem ser inventadas, construídas e formalmente institucionalizadas. $\bigcirc$ autor define tradição inventada como:

Um conjunto de práticas, normalmente reguladas por regras tácitas ou abertamente aceitas; tais práticas de natureza ritual ou simbólica, visam inculcar certos valores e normas de comportamento através da repetição, o que implica, automaticamente, uma continuidade em relação ao passado (HOBSBAWM, 2008, p. 9). 
Destaca o autor (2008a) que o fenômeno da invenção de tradições constitui-se emuma prática muito comum na história da humanidade, porém sua frequência tem sido impulsionada desde o início do século XX, precisamente antes da $1^{a}$ Guerra Mundial, como produção em massa. Categoriza o autor que tais tradições, exemplificadas por rituais religiosos; cerimônias; edifícios; monumentos e símbolos oficiais públicos (como o hino e bandeira nacional); novos feriados; heróis; vestuário e uniforme; música, propaganda, esporte; educação, entre outros, podem ser realizadas oficialmente e não-oficialmente, ou mesmo serem produtos de ambas, as quais conceitua:

As invenções oficiais- que podem ser chamadas de políticas - surgidas acima de tudo em estados ou movimentos sociais e políticos organizados, ou criados por eles; e as não-oficiais - que podem ser denominadas sociais - principalmente geradas por grupos sociais sem organização formal, ou por aqueles cujos objetivos não eram, específicos ou conscientemente, políticos (HOBSBAWM, 2008a, p. 2711 .

Para Hobsbawm (2008a, p. 271), o contexto sóciopolíticoecultural em conflito entre novos e velhos costumes põe em contrariedade a continuidade de certos valores e hábitos, situação que é propícia para a invenção de novas tradições quer sejam formais e não formais, oficiais e não oficiais, políticas e sociais, pois sempre é passível a necessidade da humanidade em "[...] criar novos instrumentos que assegurassem ou expressassem identidade e coesão social, e que estruturassem relações sociais." Como se compreende da citação feita, as tradições, por serem inventadas, são mutáveis, temporárias, podem sofrer alterações com a incorporação de outras resignificações, as quais implicam sua continuidade, ao preservar elementos de identidade, ou não, quando, então, são criadas novas tradições. Acrescenta, ainda, o autor que determinadas tradições só alcançam êxito e se perpetuam na história devido serem invenções conscientes (como as oficiais/políticas), isto é, deliberadas e sistemáticas, com um propósito político em que a eficiente e frequente transmissão delas ao público possam ser sintonizadas de imediato. Neste sentido, há um público a ser conquistado para usufruir de novos ideais e para quem é produzido determinadas tradições. Essa é arazão pela qual a população é tomada como o condicionante propulsor para o nascimento, firmação e perpetuação delas visto que se deseja inculcar nela certos costumes 
e valores considerados hegemônicos. Seria, então, a invenção de tradições uma forma de manipulação do público, como advoga Hobsbawm (2008a)?

Assim, este artigo objetiva compreender como a invenção/manutenção das tradições curriculares no ensino jurídico se estabelece em uma instituição universitária. Para tanto, buscou-se, a partir de 20 horasde observações de aulas decorridas durante um semestre letivo e entrevistas semiestruturadas a uma professora e a onze estudantes realizadas e análise documental, analisar como este ensino é percepcionado e vivido pelos participantes da pesquisa. A unidade curricular escolhida para estudo é um componente curricular obrigatório e estruturante do saber jurídico; integra o chamado núcleo duro do currículo do Curso; tem uma natureza teórico-prática sendo considerada pelos participantes da pesquisa uma das mais importantes devido seu carácter técnico e generalista ao priorizar saberes indispensáveis à prática profissional no campo jurídico, portanto, portadora de um reconhecido e prestigiado status acadêmico.

A unidade curricular é desenvolvida em trêsetapas, ofertada em três semestres letivos subsequentes cujos encontros presenciais incluem todos os dias da semana em um tempo de 50' e é oferecida em duas turmas sob a 16 regência de seisprofessores que se intercalam em aulas teóricas e práticas. A gestão da Faculdade de Direito indicou a professora participante desta pesquisa por ser considerada pela Instituição como aquela que desenvolve boas práticas de ensino além de ser a coordenadora da referida unidade curricular. A professora é concursada, situa-se no início da carreira (Professora Auxiliar), possui mais de dezanos de experiência na docência dessa unidade curricular nessa Faculdade, embora a tenha iniciado quando de seus estudos de doutoramento realizados na mesma Instituição onde, atualmente, trabalha. Sua formação volta-se, predominantemente, para a área técnico-científica ondeatua: Direito Processual Civil, sobre a qual ressente-se do pouco investimento em sua formação pedagógica uma vez que, argumenta, nunca the foi exigida pela Faculdade como requisito de ingresso e permanência na carreira do magistério superior ou mesmo para melhoria de sua prática docente, exigência muito destacada na literatura para todas as áreas do ensino superior tendo em vista a qualidade da pedagogia universitária (LEITE, 2007).

Esse desequilíbrio do investimento na formação dos professores universitários (científico/pedagógico) é fruto de uma tradição da docência fundada em uma concepção de que o domínio do saber técnico-científico da área 
especializada que o professor ensina é mais importante, portanto, suficiente, para credenciar qualquer profissional portador de um diploma de nível superior mais elevado como aquele que está apto para ser docente do ensino superior.

Vale destacarque o ensino de Direito é um campo pouco estudado pela literatura portuguesa como se podeconstatar no momento de revisão da literatura lusófona. Portanto, este artigo tem uma relevância científica como forma de contribuir para colmatar essa lacuna. Tal lacuna, em certa medida, tem favorecido para que as discussões sobre o currículo e o ensino jurídico em Portugal não alcancem, em termos de amplitude e mérito, a mesma repercussão na academia se comparada com outras áreas do conhecimento, como, por exemplo, os da área da educação e da saúde. Esse fato pode dificultar a invenção de novas tradições curriculares para esse ensino. A relação currículo e ensino é aqui perseguida assentada na convicção de que o currículo não seresume ao ensino, porém, conforme nos lembra Roldão (2003, p. 44)[...] este é uma prática essencialmente curricular porque é no ato de ensinar, e no aprender que se espera que dele resulte, que as aprendizagens pretendidas o currículo - se instituem.

\section{Declaração de Bolonha: invenção de tradições curriculares para o ensino superior europeu}

As tradições políticas mais universais inventadas no século XIX e meados do XX foram obra dos Estados dentro de seus limites histórico-geográficos, conforme destaca Hobsbawm (2008). Isso significa dizer que são obras genuinamente locais, embora possa se perceber o internacionalismo delas na atualidade, sobretudo, em decorrência da expansão e massificação dos meios de comunicação e informação, tecnologia, educacional, transporte, por exemplo. É possível concebera Declaração de Bolonha como uma nova tradição política educativa inventada, portanto, oficial, cuja institucionalização se dá por um aglomerado de países, constituindo-se em uma tradição política supranacional em que as fronteiras educativas não são mais estabelecidas pelo limite geográfico europeu. Há aqui fronteiras econômicas para o ensino superior em jogo em que está em causa a urgente necessidade de pôr em evidência no mundo cada vez mais global, novamente, a supremacia europeia nesse campo. 
ensino jurídico em contexto universitário português: tradições curriculares em debate

A necessidade de instituir reformas inovadoras no contexto do ensino superior como forma de competir no espaço europeu do ensino superior tornou-se um desafio premente para Portugal, sobretudo, em decorrência denão só adequar esse ensino aos objetivos e às recomendações da Declaração de Bolonha (SERRALHEIRO, 2005)', bem como ao processo de intelectualização do mundo contemporâneo que cria novas exigências às instituições de ensino superior europeias e, por conseguinte, aos professores e estudantes em termos de ensino, aprendizagem e formação profissional como forma de construir e reter capital humano. Legitima-se, então, uma nova tradição curricular em que o ensino superior é enaltecido como o motor de desenvolvimento econômico fundado na produção e transferência de conhecimento. Um projeto político ambicioso, competitivo e, supostamente, atrativo é inventado para o mundo o qual, refleteRobertson (2009), visa globalizar a educação superior para além das fronteiras do velho mundo, tornando-se um modelo a ser seguido pelos mercados educativos globais. Essa é arazão pela quala autora destaca quehá implicações dele para outras economias nacionais e regionais, entre elas, a de Portugal, que precisam ser analisadas.

Para Portugal, não instituir reformas educativas alinhadas a tais reco18 mendações significaria não sair da periferia europeia (LANDES, 200 1) pelo menos por um longo tempo, o que poderia minar o projeto histórico da Europa em querer se tornar a economia, baseada no conhecimento, mais competitiva do mundo do século XXI. Projeto Português, ao que tudo indica, mais uma vez adiado em face daatual crise econômica mundial que afeta tanto os países semiperiféricos quanto os ricos do continente. Goradas as intenções portuguesas, Candeias (2009) argumenta que a periferização econômica a que Portugal é sujeita é histórica, agravou-se durante o século XXl e paira como uma sombra ameaçadora neste século XXI, o que torna o ensino superior um elemento fulcral para a retomada do crescimento econômico.

Ao estar as relações de forças postas neste cenário, o recuo total de Portugal a DB seria, nos dizeres de Derovet (2009), uma emenda pior do que o soneto, ao acrescentar que um país ou uma universidade que não entrem nesse sistema serão marginalizados ou, como argumenta Robertson (2009), considerados uns forasteiros. Simultaneamente a esse debate, a obediência do estado Português à Declaração de Bolonha acarretou reformas na estrutura curricular, pedagógica e organizacional das instituições de ensino superior lusófonas visando adequar-sea uma nova tradição curricular inventada para 
esse ensino em que a mobilidade de estudantes e docentes é estimulada; a formação acadêmica passa a ser oferecida emtrêsciclos (licenciatura, mestrado e doutorado) tendo em conta a globalidade e diversidade de atividades; institui-se a adoção de um sistema de transferência de créditos curriculares $\left(\right.$ ECTS $^{3}$ ) e de qualificações comparáveis ponderadas no Quadro Europeu de Qualificações e de Acesso às Profissões. Tal mudança de paradigma de formação, por extensão, impôs, também, revisão teórica e prática aos domínios do ensino, da aprendizagem e da avaliação, reacendendo a convicção, como afirma Teodoro (2005), de que a universidade só se reforma a partir de mandatos exteriores bem explícitos.

Essa mudança de paradigma é destacada nos Decretos-Leis n ${ }^{\circ} 42$, de 22 de fevereiro de 2005; n74, de 24 de março de 2006, e n¹07, de 25 de junho de 2008, segundo os quais é necessário atender àquestão central da Declaração de Bolonha: mudança do paradigma do ensino de um modelo passivo, baseado na aquisição de conhecimento, para um modelo fundado no desenvolvimento de competências pelos próprios estudantes. Deduz-se, assim, que, para além de uma mera alteração formal, o ensino deva estar centrado nos estudantes, nas aprendizagens e na autonomia deles e não no ensino, nos professores e no protagonismo destes. Esta, talvez, seria a melhor expressão para situar o confronto entre duas tradições curriculares em confronto no ensino superior português: ambas oficiais e políticas mas distintas em termos de processos e finalidades. Pondera Leite $(2011)$ que, a despeito de que muitas práticas docentes no ensino superior já se organizassem sob esta lógica de mudança de paradigma, foi, de fato, com o discurso de Bolonha que, em Portugal, as instituições de ensino superior e seus professores passaram a dar maior atenção às questões designadas por pedagógico-didáticas, ganhando maior projeção. Contudo, como se podeobservar pelo estudo realizadoainda é um grande desafio às instituições de ensino superior portuguesas pôr em prática esse novo paradigma em que se inventa uma nova tradição curricular.

Lembram Correia e Matos (2005) que, com uma nova estrutura temporal e curricular no ensino superior português em que se altera sua organização, métodos e conteúdos idealizou-secriar processos formativos centrados no regime de autoformação dos estudantes privilegiandoa aprendizagem mais do que o ensino e a lecionação tradicional. Neste sentido, o jovem estudante pós-Bolonha precisa assumir o protagonismo do seu próprio processo formativo, assentado em uma relação pedagógica negociada e contratualizada 
com os professores, devendo adquirir competências e mobilizá-las numa base interdisciplinar em que possa revelar domínio de certos saberes; demonstrar responsabilização individual; autonomia; disciplina,tornando, assim, o ensino, aaprendizagem ea avaliação elementos importantes para a qualidade da formação profissional porque, por meio dela, pode-se ajuizar, de fato, se esse estudante é portador de tais saberes e competências profissionais, indispensáveis à competitividade do espaço europeu do ensino superior.

Portanto, uma formação mais exigente é aspirada por Bolonha. Logo, com a Declaração de Bolonha, a Europa inaugura, na contemporaneidade, o Espaço Europeu de Educação Superior configurandouma nova invenção oficial de tradição curricular europeia ao se contrapor frontalmente às tradições em vigor e a se pôr a favor de inovações pedagógicas, embora, adverte Esteves (2010), muitas delas ainda são motivos de perplexidades, quando não de rejeição.

Decerto que a Declaração de Bolonha bem como as investigações desenvolvidas no âmbito do ensino superior na Europa desencadearam, nas instituições de ensino superior portuguesas, do ponto de vista das intenções curriculares declaradas, uma necessidade de mudança de paradigma curri20 cular/formativo em que é necessário resignificar as dimensões do ensino, da aprendizagem, da avaliação e os papéis dos estudantes e professores. Cabe destacar que tal paradigma revela uma compreensão de conhecimento em que este não está enclausurado ao espaço formal de sala de aula, nem muito menos é ensinado pelo docente em suas formas convencionais de métodos e tempos, tão só. $\bigcirc$ conhecimento, nessaperspectiva, precisa ser trabalhado de forma interdisciplinar e transversal por um professor compreendido como o facilitador da aprendizagem dos estudantes, deixando de assumir uma postura central no processo de ensino, ou seja, a base do conhecimento não é mais o conteúdo em si, mas os processos de construção dele por parte dos estudantes sob a supervisão dos docentes.

Por sua vez, os estudantes são concebidos como o principal responsável pelo seu percurso de aprendizagem em que, por meio da participação em diversas atividades de ensino e de aprendizagem em sala de aula e para além dela, se favoreça o desenvolvimento de tarefas e estudos autônomos tendo em vista a autoaprendizagem, enfoque que pode levar os estudantes a vivenciar diferentes estratégias de aprendizagens. A responsabilização individual - esforço pessoal acrescido para o alcance de suas aprendizagens, é 
entendida como um forte compromisso e envolvimento com as tarefas a desempenhar, condições vitais para o sucesso acadêmico dos estudantes assim como prerrogativas para incutir uma consciência coletiva acerca da importância da educação ao longo da vida, destacada fortemente por Bolonha.

Onsino, na tradição curricular inventada por Bolonha, não está mais restrito e enclausurado às salas de aulas convencionais uma vez que o professor não possui mais o protagonismo na tarefa de ensinar os conteúdos aos moldes da tradição curricular centrada, à luz das tipologias curriculares clássicas, em um paradigma técnico. Como esse ensino não mais está centrado na figura do docente e nos espaços tradicionais que the davam abrigo, o conhecimento a ser aprendido não se resume, portanto, ao que é ensinado lá, o que obriga os estudantes a gerir suas próprias aprendizagens, isto é, a aprender autonomamente. $\bigcirc$ espaço, tempo e os processos formativos, portanto, ampliam-se e tornam-se mais complexos em uma era Pós-Bolonha à medida que a autodisciplina por parte dos estudantes é requerida como condicionante para a sua autoaprendizagem. A avaliação assume, então, uma função reguladora ao permitir que tanto os professores quanto os estudantes possam monitorar as aprendizagens. Tal perspectiva curricular induz a uma organização e desenvolvimento do processo ensino-aprendizagem em que o sucesso desse processo depende, basicamente, dos estudos, do desempenho, do interesse, da motivação, das atitudes, da participação dos estudantes, caso sejam oferecidasas condições materiais para tal.

Existe a compreensão deque a Declaração de Bolonha em Portugal originou uma nova forma de pensar e pôr em prática o ensino superior com a intenção de romper com uma certa tradição de ensino quando rejeita conscientemente "velhas" práticas pedagógicas ao mesmo tempo que se inventam novas tradições (HOBSBAWM, 2008). No que se refere ao ensino jurídico tradicionalmente veiculado nas universidades, uma de suas principais críticas assenta-se em sua terminalidade formativa ao prepararum profissional com um perfil de operador jurídico memorizador, leitor de códigos e enclausurado ao limitado esquema do silogismo interpretativo e lógico-formal do Direito positivo (FERNANDEZ; FERNANDEZ, 2005) concepção de Direito cuja base científica influencia fortemente a organização e o desenvolvimento curricular em vigor assim como também as concepções e práticas dos docentes e os profissionais lá formados em que se perpetua uma tradição científica dominante no campo jurídico e no campo pedagógico do ensino jurídico. 
ensino jurídico em contexto universitário português: tradições curriculares em debate

Enfoque que se distancia de uma tradição de ensino em que, sem o prejuízo do conhecimento do ordenamento jurídico vigente, os estudantes possam desfrutar de uma visão do Direito mais flexível, integrada e transversal, cabendo ao docente favorecer um processo ensino-aprendizagem com uma visão pluralista da sociedade, em que a abordagem multidimensional e multidisciplinar do sistema jurídico seja o elemento fundante da formação de um profissional capaz de pensar séria, global e criticamente o Direito (FERNANDEZ; FERNANDEZ, 2005).

É no quadro dessa problemática e compartilhando com as ideias de Goodson (2001) dentre as quais defende que o currículo é uma construção social e que a disciplina escolar surge como a manifestação principal do currículo, que se situa a questão que orienta a secção a seguir: o que mudou em termos de tradições curriculares no ensino jurídico com a Declaração de Bolonha? Para tanto, busca-seno Curso de Direito de uma universidade portuguesa, a partir de um estudo de uma disciplina nuclear de seu currículo, elementos para refletir sobre tal questão. Tal disciplina, em sua forma e em seu conteúdo, pode revelar um certo conhecimento pedagógico e jurídico dominante fundado e propulsor de uma dada tradição acadêmica IGOODSON,

222001 l em que, em nome da manutenção dela, enaltece-se e, portanto, preserva-se um passado dito glorioso. Assim, pergunta-se: a tradição curricular inventada por Bolonha favoreceu a ruptura de antigas tradições no ensino de Direito lusófono?

\section{O Ensino Jurídico: tradições curriculares em debate}

O estudo foi desenvolvido em um Curso de Direito da Faculdade de Direito de uma Universidade pública ${ }^{4}$ de grande prestígio acadêmico em Portugal, seja pela qualidade do seu ensino, seja porque contribuiu de uma certa forma para a construção de um conhecimento e um normativo jurídico contemporâneo bem como pelo fato de seus professores e licenciados terem alcançado um protagonismo significativo como profissionais liberais, renomados juristas e políticos consagrados. Essa é uma tradição coletiva muito destacada e perseguida pela Faculdade, o que subtende-se, pelos discursos dos participantes desta pesquisa, que é fundamental mantê-la para preservar o status que conquistaram em seu percurso histórico. Destaca Hobsbawm (2008) 
que toda tradição inventada, na medida do possível, utiliza a história como legitimadora das ações e como cimento de coesão social em que se pode a partir dela inventariar o que foi selecionado, escrito, popularizado e institucionalizado por quem estava encarregado de fazê-lo. Neste sentido, a história de sucesso é tomada como legitimadora para justificar o prestígio alcançando por essa Faculdade.

De forma orgulhosa, um gestor expressa que a Faculdade é muito procurada tendo em vista a quantidade de alunos que realizam os exames nacionais 5 , seu ponto de corte é um dos mais altos do país e ela não pode perder seu prestígio acadêmico em alusão à manutenção de uma tradição marcada pela seriedade e rigor de seu ensino e da qualidade dos profissionais que lá são formados. Portanto, a credibilidade institucional perante a sociedade portuguesa é uma decorrência dessa tradição fortemente preservada. Assim, sepresume-se que uma formação profissional recebida nessa Faculdade confere aos seus diplomados mais do que uma certificação/diploma, fornece-thes, como sublinha Goodson(200 1), uma credencial para um dado modo de viver, perpetuando-se, assim, uma tradição acadêmica em que os profissionais do Direito continuem sendo valorizados, prestigiados e reconhecidos socialmente. Daqui por diante, tal Faculdade será concebidacomo uma instituição que, sublinha Apple (1 999), incorpora tradições coletivas que cumprem determinadas finalidades humanas que, por sua vez, são produtos de ideologias sociais e econômicas concretas. É o que se pode vera seguir.

Criado no início do século XX (1911) sob a influência da Universidade de Coimbra em que se herda uma tradição de ensino favorecedora às aulas-conferências e de pôr o estudante como objeto passivo, mero receptor de informações (FRANCISCHETTO, 2010), tal Curso passou por diferentes reformas curriculares ao longo do seu percurso histórico sem, contudo, alterar determinadas tradições curriculares. A mais recente, implementada, em 2007, em decorrência da Declaração de Bolonha e das regulamentações do ensino superior português, teve como objetivo distanciar-se de uma tradição do ensino jurídico eminentemente teórico, dogmático, positivista (VILLAS BOAS, 2013), descontextualizado e unidisciplinar (FRANCISCHETTO, 2010) para assumir uma nova tradição de ensino interdisciplinar em que se busca integrar as racionalidades da Ciência Jurídica e das demais Ciências Sociais, permitindo perceber o Direito como fenômeno social e como ciência (SANTOS, 2013). Isso implica uma reformulação dos atuais paradigmas teórico-metodológicos 
ensino jurídico em contexto universitário português: tradições curriculares em debate

do ensino, da aula, da avaliação, da formação e da prática dos professores do ensino jurídico e, por conseguinte, o desafio de se inventar novas tradições curriculares está posto.

De fato, as últimas reformas curriculares desse Curso foram efetivadas de forma pontual em decorrência de ajustar a sua configuração organizacional, pedagógica e científica aos objetivos da Declaração de Bolonha em que entra em jogo uma nova estrutura curricular de curta duração, flexível, comparável e compatível com as necessidades formativas que o mundo do trabalho exige, cada vez mais competitivo, diversificado e complexo em que se busca instituir novas tradições curriculares para o ensino superior europeu.

Todavia, embora se perceba nos discursos da maioria dos gestores institucionais e de uma parte dos professores e estudantes dessa Faculdade um certo apoio a tal Declaração, seus efeitos, conjugados com as reformas curriculares implementadas, trazem, ainda, muitas dúvidas e inquietações à tradição curricular vigente o que nos leva a ponderar que, como nos alerta Dias Sobrinho (2005), uma reforma acaba produzindo sempre algum efeito, maior ou menor, de acordo com o idealizado ou não.

24 nidade acadêmica vive, configurando-se em um dilema curricular entre o prescrito (currículo oficial) e o real (currículo em ação) que, em prol da manutenção de certas tradições, vê-se o currículo e o ensino jurídico como campos destituídos de mudanças e inovações pedagógicas em que determinadas tradições curriculares são, certamente, conservadas para atingir os fins formativos que perseguem, pois, em nome dessa manutenção, ressalta um gestor: não podemos deitar fora nosso patrimônio, nossa tradição. Às tradições curriculares antiquadas, não comportam um sentido depreciativoa certas tradições que ainda circulam no espaço do ensino superior, mas somente para destacar, como alerta Sacristán (2013), que há outras formas alternativas às tradicionalistas de ensinar.

Entre o apoio e a crítica à Declaração de Bolonha, pode-se inferir a partir dos depoimentos de alguns participantes desta pesquisa que a implantação de Bolonha no país e, particularmente, nessa Faculdade foi um grande desastre, sob o argumento de que em Portugal ninguém quis abrir mão de seus privilégios, portanto, de certas tradições de ensino inventadas historicamente já consagradas como ideais. Taisconstatações encontram guarida na reflexão de 
Nóvoab quando argumenta que a Declaração de Bolonha no ensino superior lusófono

[...] está a correr mal, porque há muita cosmética e pouca mudança efetiva... pois não se tocou no aspecto central: uma nova organização do trabalho universitário, centrado nos estudos, na aprendizagem e na proximidade às práticas de investigação (SANTOS, 2012, p. 638).

Nessa Faculdade, os efeitos da Declaração de Bolonha além de ampliar a abertura do ensino jurídico a mais estudantes e alterar alguns aspectos da estrutura curricular do Curso (diminuição do tempo formativo de cinco para quatro anos, do número de unidades curriculares, da carga horária e do conteúdo; instituição de trêsciclos integrados: licenciatura, mestrado e doutoramento; aplicação do Sistema Europeu de Crédito -ECTS), não alterou a essência do Curso, ou seja, a tradição curricular que diz respeito às concepções e práticas da produção e socialização do conhecimento jurídico (no conteúdo epistemológico e metodológico), bem como as relações hierárquicas e de poder, ambas materializadas no processo ensino-aprendizagem. Logo, cristaliza-se na Instituição uma compreensão de que é difícil e complexo mudar o que já está posto cuja dificuldade de implementar novas mudanças curriculares contribui para consagrar obsoletos costumes pedagógicos e científicos os quais são, certamente, conservados. É por suposto que o referido pronunciamento do gestor revela a inflexibilidade ou inamovibilidade das estruturas dos Cursos de Direito, conforme constatam, também, Fernandez e Fernandez (2005).

Isso não significa, entretanto, que há um consenso acerca do ensino de Direito nessa Faculdade, visto que, por ocasião do período de produção dos dados desta pesquisa, participamos como ouvinte de uma Jornada Pedagógica intitulada Reforma do Regulamento de Avaliação7, oportunidade que a comunidade acadêmica teve para expressar suas impressões e propostas acerca do processo ensino-avaliação-aprendizagem lá desenvolvido. Uma das questões debatidas acaloradamente nesse Evento e que se relaciona com o objetivo deste artigo diz respeito ao domínio do ensino, concebido e desenvolvido a partir de uma organização específica, nomeadamente: composição docente; número, local de desenvolvimento e natureza das aulas; papel dos professores e estudantes; avaliação, favoráveis, ao que tudo indica, àmanutenção de uma 
ensino jurídico em contexto universitário português: tradições curriculares em debate

tradição curricular em que se projeta a perpetuação de um ensino lecional ao "estilo Coimbrã"8.

\section{Manutenção das tradições curriculares ao estilo Coimbrã: um ensino lecional/magistral}

$\bigcirc$ que se podededuzir, então, de um ensino lecional/magistral em um Curso de Direito a partir das observações em sala de aula e dos depoimentos dos participantes da pesquisa?

A concepção de um ensino lecional está associada a uma tradição de ensino centrado na figura da professora ao assumir um papel de preceptora, sendo a aula expositiva o método exclusivo para o repasse do conhecimento jurídico de cunho normativo, configuração ainda muito presente em diversos contextos internacionais, como alertam Fernandez e Fernandez (2005). Sem oferecer oportunidades de atividades de ensino interativas e coletivas, tal tradição de ensino contribui para tornar os estudantes um objeto receptivo e passivo que escuta atenta, e, respeitosamente, a preleção da professora. Tais autores 26 afirmam que, tradicionalmente, nas Faculdades de Direito ensina-se um conjunto de normas jurídicas que formam o Direito Positivo de uma determinada sociedade, portanto, acrescentam os autores que falar de Direito, nessa perspectiva, significa falar de normas, quer dizer, somente se considera Direito o que for norma, lei, sobretudo, produzida pelo estado, negando-se o pluralismo jurídico.

Essa tradição de ensino que, ao que tudo indica, os docentes não procuram distanciar-se como argumenta um professor, pode ser interpretada como fruto de uma tradição curricular em que o ensino restringe-se a reproduzir um conhecimento jurídico normativo destituído de qualquer valor social e político para os estudantes. Nesse tipo de tradição, a qualificação da aprendizagem é resumida à capacidade de o estudante demonstrar nas avaliações se assimilou disciplinadamente o conhecimento ensinado, ou seja, ensinar significa ditar o conhecimento pela professora e aprender significa escutar, copiar, decorar, reproduzir nos exames e provas o que supostamente aprendeu, caracterização que o saudoso e inesquecível Freire (1987) denominou de educação bancária. Dessa tradição, deriva-se toda uma cadeia de valores que passa a considerar a aula como centro irradiador da vida acadêmica da Faculdade, de tal sorte 
que é, a partir dela, através dela e, chegando-se a ela, que os objetivos propostos nos Programas das Disciplinas e no Plano de Curso da Instituição seriam alcançados, marcando o ritmo do andamento do currículo.

Entendida a aula como motor propulsor do processo ensino-aprendizagem, determinou a Faculdade que o conhecimento jurídico deva ser dividido em um componente teórico e outro prático para sermais bem ensinado tendo em vista o número de alunos excessivo por turma, justifica o gestor, derivando desse ajuste a separação das aulas em teóricas e práticas; turmas teóricas e práticas; professores de aulas teóricas e práticas, assumindo estas, funções muito distintas e claras. Estabelece-se, assim, a cisão teoria e prática, com a primazia da prática em números de horas em detrimento da teoria, tão danosa para a organização do trabalho pedagógico na medida em que o saber jurídico é dividido e compartimentalizado. Todavia, são as Aulas Teóricas (AT) as mais consagradas pela tradição curricular vigente dessa Faculdade não só porque constituem a nobreza do ensino como também porque são os professores mais experientes, conceituados e renomados que as ministram. Não é de se surpreender, pois, que tal tradição conserva uma hierarquia de saberes, disciplinas e professores.

As aulas teóricas foram ministradas por três professores da unidade curricular em um tempo diário de 50' e eram realizadas em um Anfiteatro porque abriga um número maior de estudantes. Tais docentes pertencem à carreira do magistério superior ${ }^{9}$, possuem um certo status e prestígio institucional e intercalam-se nas aulas teóricas ao longo do semestre letivo, sendo cada um responsável por um conjunto de conteúdos escolhidos mediante as suas especialidades e preferências. As aulas teóricas objetivam trabalhar teorias, doutrinas e conceitos do campo das ciências jurídicas. Nessa tradição curricular, o ensino volta-se para a professora ministrar a matéria obedecendo a uma sequenciação e aumento de grau de complexidade do conhecimento jurídico em estudo. Essas aulas são as mais valorizadas pela comunidade acadêmica porque precisam ser aulas magistrais, possibilidade que os alunos têm em aprender com quem mais sabe, defende de forma convicta um professor, discurso recorrente e enaltecido pela tradição curricular inventada ao estilo Coimbrã.

Nas aulas teóricas, constata-se a impossibilidade de os docentes desenvolverem qualquer atividade em que haja a participação ativa dos estudantes para que possam interagir com os professores e com os colegas de 
ensino jurídico em contexto universitário português: tradições curriculares em debate

turma acerca do conhecimento em estudo, bem como realizar eventos de avaliação da aprendizagem, ao que tudo indica, exclusividade das aulas práticas. Os depoimentos de professores de que as aulas teóricas são plenárias, visto que é veiculadoum ensino lecional em que o professor explana um conteúdo e expõe sua sabedoria a partir de uma forte relação hierárquica entre docentes e discentes, podem ser fortes indícios de uma tradição de ensino rígido, como ponderam os estudantes participantes da pesquisa. Todavia, certos professores manifestam-se, desfavoravelmente, a esse tipo de aula teórica ao expressarem sua indignação: os alunos não são ativos nas aulas teóricas; tenho profundo desgosto das aulas teóricas pois elas são sempre vazias; as aulas teóricas não são nada mais do que a leitura de manuais por parte dos professores por isto que os alunos não vão. Valedestacar que essa insatisfação pode ser interpretada como um discurso que tenta chamar a atenção dessa Faculdade para que uma nova tradição curricular possa ser inventada.

A tradição de ensino centrada na transmissão do saber por meio de aulas expositivas monologais edifica um ensino em que a professora assume o protagonismo na condução das aulas, as quais se resumem, do ponto de vista metodológico, àleitura de manuais, códigos e apontamentos em que se 28 explana um conteúdo teórico com raríssima participação dos estudantes no processo de construção da aprendizagem. Essa situação reflete o entendimento institucional e, especificamente, da professora participante da pesquisa quando concebe que as aulas teóricas são aulas de exposição.

Adverte, porém, um docente que tal tradição faz com queos estudantes fiquem desinteressados pela reflexão teórica em que deixam de frequentar as aulas teóricas, abandonando-as. Sem desenvolver estratégias de ensino e atividades diversificadas em que se possa estabelecer o diálogo, a interação e interlocução nessas aulas entre os estudantes, entre eles e a professora e entre todos e o conhecimento, o trabalho isolado instaura-se com a impressão de que, nas aulas teóricas, não é possível que os discentes manifestem suas dúvidas e opiniões, levantem perguntas, interponham questões à professora, tarefas reservadas às aulas práticas, sendo esta o local natural para que elesdemonstrem o que aprenderam ou o que precisam aprender mais e melhor.

Com a divisão do trabalho pedagógico posta na estrutura curricular do Curso, os estudantes inscritos nas aulas teóricas são subdivididos em pequenos grupos por subturmas para frequentar as aulas práticas as quais são trabalhadas por professores de início de carreira lembora raro, podem ser os 
que ministram também as aulas teóricas) ou por outros profissionais ${ }^{10}$, em um tempo também de 50'. As aulas práticas são ministradas em salas de aulas menores e voltam-se exclusivamente para aplicar os conceitos e as doutrinas estudadas nas aulas teóricas em casos jurídicos práticos ${ }^{11}$, selecionados pela professora ou pelos estudantes em sites jurídicos os quais são comentados à luz do Direito. Essa configuração é fruto da concepção institucionalizada e da própria professora de que, nas aulas práticas, trabalha-se com casos práticos.

Nas aulas práticas observadas, o método de ensino predominante também foi o expositivo, cuja finalidade era aplicar a teoria na prática, configurando um campo de aplicação da teoria visto que se subentende, como afirma a professora, que elas têm uma aplicação prática. Nessa tradição, o ensino centra-se exclusivamente na apresentação por parte da professora, de forma ditada aos estudantes, de um conjunto de casos jurídicos para que estes possam aplicar a teoria, conceitos, doutrinas, regras e leis estudados nas aulas teóricas aos casos práticos. Essa tradição de ensino assenta-se na crença da docente de que o curso de Direito volta-se para analisar casos concretos. Assim, a aplicação da teoria aos casos práticos é feita a partir de comentários pontuais expressos pela professora com a ajuda de um normativo jurídico (códigos e leis) bem como pelo lançamento de inúmeras perguntas à turma sempre voltadas para as questões técnico-legalistas do Direito, sobre as quais a docente insiste para que haja respostas por parte dos estudantes.

Essa situaçãoleva a pronunciar, também, comentários muito pontuais sobre as intervenções deles. Essa conduta cumpre uma função primordial no processo avaliativo, já que, nas aulas práticas, os estudantes têm a possibilidade de responder às perguntas formuladas pela professora, eliminamdúvidas e fazem perguntas (raramente), sempre de forma individual, razão pela qual é exigidauma participação ativa deles porque é, por meio dessas atividades (avaliação contínua), conjugadas com os exames finais (avaliação somativa), que eles serão avaliados. Logo, deposita-se, nas aulas práticas, um valor significativo às aprendizagens dos estudantes visto que é por intermédio delas que se verificam se os alunos estão aprendendo ou não, defende a professora, isto é, verifica-se se os discentes aplicam corretamente a lei no caso jurídico em estudo ao demonstrarem capacidade para elaborar peças e esquemas estritamente prático-legalistas. Essa constatação encontra respaldo em Fernandez e Fernandez (2005) ao afirmarem que, tradicionalmente, nas Faculdades de Direito ensina-se um conjunto de normas jurídicas que formam o Direito Positivo 
ensino jurídico em contexto universitário português: tradições curriculares em debate

de uma determinada sociedade, portanto, acrescentam os autores que falar de Direito, nessa perspectiva, significa falar de normas, quer dizer, somente se considera Direito o que for norma, lei, sobretudo, produzida pelo estado, negando-se o pluralismo jurídico.

É suposto que exista relevância nas aprendizagens dos estudantes de Direito quando estes aplicam conceitos, teorias e doutrinas a casos jurídicos práticos os quais expressam um saber oriundo dos tribunais ou das atividadesadvocatícias. Tais supostas aprendizagens podem, no entanto, estar sendo conduzidas por uma unidade curricular sem qualquer rigor científico, dotada de um ecletismo teórico e muito dependente da moral e da política (KALIL, 2012). Ademais, é de se destacar que estudar casos práticos jurídicos fazendo-se referência, apenas, ao ordenamento jurídico subjacentes a eles pode-se perder a oportunidade de aprofundar, do ponto de vista antropológico, histórico, econômico, político, ético, os problemas sociais que os provocaram, passando-se a aplicar o Direito como resposta/solução definitiva à questão em litígio, isto é, restringe-se o ensino jurídico a analisar se tais casos estão ou não em conformidade com as leis vigentes. Ponderam Fernandez e Fernandez (2005) que a mera informação de caráter estritamente instrumental faz com que, com o pas30 sar do tempo, a ausência de raciocínio crítico e problematizante terminem por esclerosar um conhecimento jurídico setorizado em múltiplas áreas de especialização, ao que tudo indica, danosa à formação dos profissionais do Direito.

Com essa desenvoltura, as aulas práticas transcorrem-se e perpetuam uma tradição de ensino em que a professora transmite um conteúdo em um tom monocórdico, ininterrupto, sequencial e intermitente, ainda que ela demonstrasse ser profunda conhecedora do saber jurídico que ensina, requisito em que se persiste a ideia de que o fundamental para o professor universitário é dominar o conteúdo específico de sua área de modo a poder transmiti-lo aos estudantes (LEITE, 2007). Não é de se estranhar, portanto, que, estabelecida a cisão entre teoria e prática, a professora não faça referência, nas aulas práticas dos conteúdos ensinados nas aulas teóricas por ela própria e pelos demais professores, não se percebendo, portanto, vínculos, relações, integrações entre estas e com as demais unidades curriculares, as quais decorrem sem nenhuma novidade e criatividade metodológica, reguladas pelo relógio que marca um ritmo de trabalho monocórdico. Assim, se compreende que os estudantes tornavam-se meros expectadores e receptores desse saber. Neste sentido, a diversidade metodológica e a variação de técnicas do ensino, entre 
outros, podem ser tomadas pela docente como uma nova agenda de trabalho contribuindo para que a turma participasse e interagisse mais entre si e com a ela, imprimindo às aulas outras dinâmicas mais interativas e ativas.

Em síntese, tanto nas aulas teóricas quanto nas aulas práticas observadas, a professora organiza o ensino para que os estudantes obtenham conhecimentos básicos e elementares da área de saber especializado em questão. Vale destacarque os conteúdos ensinados restringe-se a um elenco normativo estabelecidos em uma ordem sequencial partindo-se dos mais gerais para os mais específicos, em que são consultados as leis e os seus respectivos dispositivos, sem indícios do aporte de outras ciências, o que pode redundar em uma formação profissional de técnicos em leis divorciados de uma preocupação com os problemas sociais e suas soluções (FRANCISCHETTO, 2010).

É interessante destacar o fato de que nunca houve um registro escrito pela professora acerca do conhecimento ensinado nas aulas observadas pois todo o seu discurso era proferido oralmente, e osestudantes, com seus cadernos e o código abertos em cima da mesa, ouviam disciplinadamente e faziam anotações das quais não se percebia nenhuma discordância. Essa negação da expressão escrita nas aulas é justificada pela professora tendo em vista supor que os estudantes se tornariam mais autônomos nos processos de estudo e aprendizagem, como forma de atender aos princípios que propugna a Declaração de Bolonha referindo-se a uma formação centrada na aprendizagem, ou seja, no estudante, e não mais no ensino, no professor. Desta forma, a professora argumenta que evita dar os chamados apontamentos (em alusão aos conteúdos), que em geral, diz ela: é uma coisa que os alunos adoram mas que eu acho que é muito mau, porque quero que eles aprendam e leiam pelos livros.

A tradição curricular que Bolonha deseja implementar ainda não se fez presente na unidade curricular observada, pois muito longe de atender a tais princípios, esse ensino desenvolve-se sem novidades/variação do ponto de vista metodológico e epistemológico. Não há alterações da dinâmica da sala de aula, não há auxílio de recursos didáticos para além do código civil e de seu fichário, não há trabalhos de grupo na sala e para além dela, o que redunda numa participação apática por parte dos estudantes e, quando há, argumenta a professora que ela é fraca, pois a maior parte dos alunos tem alguma deficiência de base, não tem grandes hábitos de estudos; não são 
ensino jurídico em contexto universitário português: tradições curriculares em debate

muito participativos nas aulas; estão desmotivados e à espera que eu thes dê todos os elementos, imputando aos estudantes uma considerável parcela das mazelas do ensino jurídico.

A professora pondera que, se tivesse um contexto curricular mais favorável ao desenvolvimento de atividades metodológicas diversificadas que favorecessem a participação dos estudantes de forma mais autônoma, privilegiaria a investigação ou análises de trabalhos específicos sobre diversos temas, contudo acrescenta a professora, que,com esse gênero de alunos, isso é um bocadinho difícil motivo pelo qual o trabalho de investigação por parte dos estudantes não foi um elemento considerado nessa unidade curricular. Se reconhece a importância da investigação quando integrada ao ensino, visto que um ensino universitário dispensado/desligado da investigação tende a não ser mais do que um ensino secundário avançado (ESTEVES, 2010).

Essa forma de desenvolver o ensino pode ser explicada, em certa medida, em decorrência de como o currículo e o ensino jurídico são concebidos, organizados, planejados e vividos os quais favorecem não só a valorização de uma certa tradição curricular como também fervorosamente é mantida em prol de um passado glorioso e de sua consagração, afinal é

32 o sistema de minha Faculdade, justifica a professora. Todavia, tal professora admite, também, que essa condução do ensino é uma limitação pessoal de sua parte, numa alusão ao passado (porque assim foi formada) como também ao presente (é deste jeito que vê os colegas de trabalho ministrarem aulas), repetindo-se em suas práticas porque, provavelmente, concorda com o pensamento pedagógico do ensino jurídico vigente na Instituição que trabalha.

Assim, com tal repetição, cumpre-se uma característica das tradições que é a invariabilidade de certos costumes, conforme analisa Hobsbawm (2008a). Para esse autor, a invenção de tradições é essencialmente um processo de formalização (no caso em estudo, pelo currículo oficial) e de ritualização (posto em evidência pela ritualização das práticas docentes) em que se busca perpetuar o passado considerado glorioso, não obstante aimposição da repetição.

A experiência pedagógica vivida na condição de discente e, depois, na docência, neste caso, se confirma como o principal lócus de formação docente para essa professora, ao que tudo indica, limitadora de uma pedagogia universitária mais qualificada. É com essa compreensão que 
se podeperceber os argumentos da professora para justificar a aceitação e manutenção de uma dada tradição curricular no ensino jurídico o que, provavelmente, pode dificultar a invenção de uma nova tradição curricular mais condizente com um ensino jurídico interdisciplinar e crítico, invenção que pode debilitar ou destruir padrões sociais (velhas tradições), como pondera Hobsbawm (2008).

Essa marca pessoal da docência, fruto da sua formação (como estudante e, posteriormente, professora do Curso de Direitol e experiência profissional, no campo jurídico, traz um tom muito peculiar à relação pedagógica estabelecida entre ela e os estudantes, extremamente: impessoal, distante e formal, o que demarca claramente a autoridade de que é portadora, mantendo-se, com essa postura, as tradições curriculares vigentes. A professora ressalta que o fato de não ter uma relação muito próxima com seus estudantes deriva da sua maneira de ser, isto é, porque não é do tipo de professora companheira. Mas, logo deixa evidentea convicção que funda tal distanciamento quando acredita que deve existir alguma distância entre o professor e o aluno, pois não quer ser uma professora que facilite o trabalho dos alunos.

Uma outra consequência decorrente da cisão teoria e prática assenta-se no fato de que o conhecimento técnico fora trabalhado pela professora destituído do enfoque político ao ensinar o conteúdo jurídico de forma objetiva, técnica, imparcial, impessoal, aparentemente neutra, sem nenhuma problematização sociopolítica, tradição curricular ainda muito presente nos Cursos de Direito em que, como afirma Kalil (2012), há o predomínio de disciplinas dogmáticas (certeza da razão) em detrimento das não dogmáticas. Pela expressão oral e corporal da professora, não se percebeu, em seu ensino, indícios de qualquer análise e posicionamento sociopolítico sobre o conhecimento jurídico ensinado, deixando dúvidas acerca dateoria jurídica e educativa que fundamenta seu trabalho como profissional do Direito e professora.

Ao restringir seus relatos e comentários a destacar pontos técnicos e operacionais da legislação em vigor e de casos jurídicos, reduz-se o saber a uma racionalidade técnica o que reforça a compreensão da tradição do ensino de Direito em vigor de que o profissional lá formado precisa conhecer a jurisprudência (as normas) dominante nos tribunais sem indagar de sua validade ou mesmo eficácia, desprovidas de qualquer valoração (FRANCISCHETT, 2010 ). Nessa perspectiva, o ensino reproduz, também, a cisão entre a dimensão técnica e política do conhecimento, indispensável para a compreensão da 
ensino jurídico em contexto universitário português: tradições curriculares em debate

práxis humana à luz do Direito. Refletem Fernandez e Fernandez (2005) que resumir a ciência do Direito a uma relação direito/norma destituída de um contexto social e cultural mais amplo é uma visão reducionista. Ressaltam, ainda, os autores que secontrapondo a tal compreensão está a ideia de que a medida e a essência do Direito é o humano nas suas mais variadas formas de manifestação no mundo, portanto, compreender a natureza humana seria o conteúdo e a função do Direito, constituindo-se em um princípio a ser incorporado por uma outra tradição curricular para o ensino jurídico.

De maneira geral, a tradição curricular ao estilo Coimbrã assenta-se na perspectiva da teoria curricular técnica aos moldes como refletem Apple (1 999) e Pacheco (2005) a qual é fruto da hegemonia do positivismo normativista enquanto princípio paradigmático da organização dos Cursos de Direito que cinde teoria e prática; ensino e investigação; conhecimento técnico e político. As características principais dessa teoria curricular, na perspectiva de Pacheco (2005), restringem-se a discussão técnica do currículo e ao forte pendor do controle burocrático tanto sobre o conhecimento quanto sobre a forma de organizá-lo. Destaca Apple (1999) que essa teoria curricular continua a influenciar a área do currículo contemporâneo em muitos campos do saber, 34 entre eles, como observado nesta pesquisa, a do Ensino do Direito em estudo, razão pela qual este, aparentemente hegemônico, reproduz um ensino em que a neutralidade; a imparcialidade; a abstenção de juízos de valor; o conhecimento jurídico trabalhado como uma verdade única, portanto, entendido como perfeito; o foco nas leis emanadas pelo estado português, constituem-se emmarcadores de uma forte tradição curricular ainda vigente.

Essa tradição perpetua uma compreensão de que todo o Direito pode ser ensinado desde que sejam oferecidasas condições materiais para a transmissão das premissas básicas do sistema jurídico por meio de um conjunto de disciplinas introdutórias e ordenadas em uma sequência etapista, veiculadora de um teor de cunho disciplinar-técnico-normativo, cuja função é menos de formar os estudantes e mais a de lhes informar de maneira estereotipada e padronizada, sobre a linguagem necessária ao aprendizado da dogmática, fazendo com que o Direito se apresente (para o estudante) como uma série de dados sem vinculação entre si (FERNANDEZ; FERNANDEZ, 2005). O conhecimento jurídico, portanto, restringe-se ao conhecimento do sistema legal, ao mundo das leis e dos códigos, cabendo aos estudantes saber aplicá-los. 
Com efeito, um ensino jurídico com enfoque unidisciplinar, como observado, possibilita poucas oportunidades para análises fundadas a partir do contributo de outras ciências tendo em vista a compreensão do fenômeno jurídico numa perspectiva plural, desafio a ser conquistado por uma nova tradição curricular. $\bigcirc$ distanciamento do Direito das demais ciências humanísticas tem sido uma questão levantada por certos estudiosos para explicar a tradição curricular disciplinar em que o conhecimento jurídico é encastelado, ocasionando um isolamento teórico e uma rigidez interpretativa como ponderam Fernandez e Fernandez (2005), ainda predominante em muitos Cursos de Direito.

Para Nobre (2003), citado por Kalil (20 12), a origem dessa concepção curricular reside no fato de que o Direito historicamente constitui-se emum campo disciplinar de status, prestigiado, onipotente, considerado a ciência rainha ou um deus (ubiquidade divina) a ponto de não seroportuno recorrer às outras ciências em uma perspectiva transdisciplinar e transversal favorecedora de outra tradição curricular para o ensino jurídico. Para compreender essa perspectiva da ciência do Direito Positivo, destaca Apple (1999) que uma ciência não é só uma área de conhecimento ou técnicas de descoberta e formulação de justificações é, também, um grupo de indivíduos à procura de elaborar projetos de mundo. Nesse sentido, o autor acrescenta que, por ser a ciência um campo em disputa e conflituoso, portanto, histórico, o trabalho científico pode estar sempre ligado a padrões considerados válidos e é visto (e ensinado) como estando sempre sujeito à verificação empírica sem influências externas, quer pessoais ou políticas, como constatado.

O processo de ensino e aprendizagem jurídico analisado apresenta-se em contradição como que apregoa a Declaração de Bolonha em seus princípios formativos bem como o que pondera a teoria crítica do currículo porque se assenta em uma tradição curricular que, pelo seu teor dogmático e pragmático, aproxima-se deuma teoria educativa denominada por Paulo Freirede educação bancária. Tal tradição perpetua-se, sobretudo, a partir das configurações hegemônicas epistemológicas (Ciência do Direito) e pedagógicas (Ensino de Direito) e por meio da formação e experiência dos professores e dos estudantes. Com efeito, a manutenção das tradições curriculares ao estilo Coimbrã é ardorosamente perseguida pela comunidade acadêmica como forma de consagrar, ainda mais, seu prestígio no cenário universitário português. Compreende-se que novas tradições curriculares para o ensino jurídico são sempre necessárias de ser inventadas quando os velhos usos (pedagógicos) ainda se conservam 
ensino jurídico em contexto universitário português: tradições curriculares em debate

(HOBSBAWM, 2008a) como se podeperceber na perpetuação das tradições curriculares ao estilo Coimbrã na Faculdade de Direito em questão.

\section{Conclusões}

Um ensino de Direito, ao cindir teoria e prática; ensino e pesquisa; conhecimento técnico, científico e político, marca-se por manter uma tradição curricular em que a educação jurídica é pautada pela racionalidade técnica muito dependente de uma tradição científica assentado em um ideal positivista em que se perde a possibilidade de formar um profissional atento para as questões éticas, filosóficas, políticas, culturais e sociais do Direito. Foi possível visualizar a partir das análises efetuadas que em tal forma de tradição curricular projeta-se um ensino jurídico pautado em uma visão cartesiana com uma divisão do conhecimento (teóricos: conceitos de ordenamento jurídico e práticos: aplicação de leis) em que este precise ser separado, decomposto e compartimentalizado em subconjuntos para ser mais bem explicado, ensinado e estudado numa perspectiva especializada.

Tal explicação é mais adequada ao método expositivo lecional e monologal em que se desenvolve um ensino descontextualizado e unidisciplinar em que a aula expositiva é a grande, se não a única, estratégia didática para a transmissão do saber jurídico. Nesse sentido, os professores assumem-se como o centro irradiador desse saber, restringindo os estudantes ao papel de objetos de suas aprendizagens, numa relação pedagógica vertical e hierárquica em que o poder está na base da incontestabilidade por parte destes últimos do processo ensino-aprendizagem que vivenciam. Dessa tradição curricular, deriva: a) uma divisão do trabalho entre os professores estabelecida pelo mérito e prestígio acadêmico, razão pela qual os mais titulados e prestigiados incumbem-se das aulas teóricas, consideradas as mais importantes devido a sua função lecional: ensinar/explanar teorias e conceitos do campo jurídico sobre os quais se expõe, também, a sabedoria e o poder de que são portadores.

Os professores de início de carreira e demais profissionais, situados hierarquicamente em posição inferior aos demais, ministram as aulas práticas, subvalorizadas, em que se busca aplicar a teoria, regras, doutrinas, conceitos a determinados casos jurídicos práticos; b) um ensino unidisciplinar, motivo 
pelo pela qual não se percebe uma relação e integração entre as aulas teóricas e práticas, entre o conhecimento técnico e político e entre o Direito e as demais ciências que os alimenta, situação que contribui para materializar um perfil de estudante provavelmente acrítico acerca do saber e do ordenamento jurídico; c) uma estrutura curricular em que se reproduz a estrutura positiva do Direito, tal como foi concebida, historicamente, (mera expressão normativa), evidenciando uma estreita relação epistemológica entre a ciência jurídica e o seu ensino.

Toda discussão curricular é uma conversação complexa (PINAR, 2007) porque é um território contestado onde transitam diferentes identidades, culturas, subjetividades, tornando umlocal de conflito, de contradições e de relações de poder. Assim, é pertinente que as instituições de ensino jurídico tenham em mente o propósito educativo do currículo (PINAR, 2007), isto é, compreender que as relações entre o conhecimento, a sociedade, a cultura e os processos de formação de professores e estudantes do ensino superior, sobre os quais estes constroem sentidos e significados, são elementos indissociáveis e estruturantes de suas práticas, quer sejam jurídicas ou educativas. Conclui-seque a necessidade de mudança de tradição curricular, no ensino jurídico estudado, é premente sob pena de não se instituir uma formação (mais) humanística, interdisciplinar, contextualizada e democrática para os profissionais lá formados.

\section{Notas}

1 Projeto: Avaliação, Ensino e Aprendizagens no Ensino Superior em Portugal e no Brasil: Realidades e Perspectivas, financiado pela Fundação para a Ciência e a Tecnologia - FCT (PTDC/CPECED/1 14318/2009) e desenvolvido na Unidade de Investigação e Desenvolvimento em Educação e Formação do Instituto de Educação da Universidade de Lisboa, sob a coordenação do Prof. Dr. Domingos Fernandes.

2 Passado o prazo (2010) para o alcance dos objetivos da declaração de Bolonha (1999) e das Agendas de Lisboa (2000, 2005): consolidar e enriquecer a cidadania europeia; promover o desenvolvimento social e humano; promover a empregabilidade e a competitividade europeia, resta-nos indagar se a Europa e, particularmente, Portugal, conseguiram alcançar tais objetivos e se seus sistemas educativos tornaram-se referências mundiais de qualidade na nova economia global frente aos outros sistemas de ensino superior mais competitivos, portanto, mais atrativos, como o caso americano, chinês e australiano, por exemplo.

3 ECTS - european credit transfer system. Sistema de créditos curriculares em que a unidade de medida do trabalho do estudante pode assumir uma diversidade de formas (sessões de ensino de 
ensino jurídico em contexto universitário português: tradições curriculares em debate

natureza coletiva; sessões de orientação pessoal de tipo tutorial, estágio, projetos, trabalhos de campo, estudo, avaliação, atividades complementares, entre outras) e tempos formativos (horas de contatoscoletivos e presenciais e horas de estudos individuais). Family Feud é um programa de televisão americano no qual duas famílias competem para adivinhar as respostas mais populares de enquetes feitas a um grupo de aproximadamente cem pessoas.

4 A Faculdade é a maior do país em número de estudantes.

5 Os Exames Nacionais do Ensino Secundário são realizados pelo Ministério da Educação e Ciência e constituem-se como instrumentos de avaliação somativa externa obrigatórios aos estudantes dos $11^{\circ}$ e $12^{\circ}$ anos de escolaridade que visam certificar a aprendizagem realizada bem como permite a candidatura ao ingresso no ensino superior público, com um peso de $50 \%$. A classificação final do ensino secundário expressa pelas escolas equivale aos outros 50\%.

6 Reitor da Universidade de Lisboa nos períodos de 2006 a 2009 e 2009 a 2013.

7 Iniciativa da Associação Acadêmica e do Conselho Pedagógico.

8 Tradição curricular inventada pela Universidade de Coimbra que influenciou os demais Cursos de Direito lusófonos e também, por óbvio, os das antigas colônias portuguesas.

9 Os professores de carreira ministram preferencialmente aulas teóricas e, às vezes, as práticas também.

10 Os Assistentes, Assistentes Convidados, Assistentes Estagiários, Monitores ministram as aulas práticas e raramente as aulas teóricas.

11 Método dos casos: dispositivo pedagógico em que casos verídicos ou verossímeis são estudados à luz do Direito pelos discentes. Tradição curricular que teve início na Faculdade de Direito da Universidade de Harvard, ainda no século XIX, como informa Esteves (2010).

\section{Referências}

APPLE, Michael. Ideologia e currículo. Porto: Editora Porto, 1999.

CANDEIAS, António. Educação, Estado e mercado no século XX: apontamentos sobre o caso português numa perspectiva comparada. Lisboa: Edições Colibri, 2009.

CORREIA, João Alberto e MATOS, Manuel. Prefácio. In: SERRALHEIRO, José Paulo (Org.). O Processo de Bolonha e a formação dos educadores e professores portugueses. Porto: Profedições, 2005.

DECLARAÇÃO DE BOLONHA. In: SERRALHEIRO, José Paulo (Org.). O Processo de Bolonha e a formação dos educadores e professores portugueses. Porto: Profedições, 2005.

DEROUET, Jean-Louis. $\bigcirc$ outro lado da implementação do LMD em França: um novo quadro para pensar as políticas de educação e de formação. Revista Lusófona de Educação, Lisboa, v. 13, n. 13, p. 3 1-47, 2009. 
DIAS SOBRINHO, José. Dilemas da educação superior no mundo globalizado. Sociedade do conhecimento ou economia do conhecimento? São Paulo: Casa do Psicólogo, 2005.

ESTEVES, Manuela. Sentidos da inovação pedagógica no ensino superior. In: LEITE, Carlinda (Org.). Sentidos da pedagogia no ensino superior. Porto: CllE/Pivpsic, 2010.

LANDES, David Saul. A riqueza e a pobreza das nações: porque são algumas tão ricas e outras tão pobres. Lisboa: Gradiva, 2001.

FERNANDES, Domingos, FIALHO, Nuno. Dez anos de práticas de avaliação das aprendizagens no Ensino Superior: Uma síntese da literatura (2000-2009). In: LEITE, Carlinda. ZABALZA, Miguel (Org.). Docência universitária: ensino superior: Inovação e qualidade na docência. Porto: CllE da Universidade do Porto, 2012.

FERNANDEZ, Atahualpa, FERNANDEZ, Marly. $\bigcirc$ ensino do Direito, a formação do jurista e as escolas superiores. Revista Jus Navigandi - Doutrina e Peças, 2005. Disponível em: http://www.jus.com.br. Acesso em: 27 fev. 2013.

FRANCISCHETTO, GilsilenePassonPicoretti. Em busca de novos saberes: uma aproximação entre o ensino jurídico e a pedagogia. In: FRANCISCHETTO, Gilsilene Passon Picoretti (Org.). Ensino jurídico e pedagogia: em busca de novos saberes. Curitiba: Editora CRV, 2010.

FREIRE, Paulo. Pedagogia do oprimido. 33. ed. Rio de Janeiro: Paz e Terra, 1987.

GOODSON, Ivor. O currículo em mudança: estudos na construção social do currículo. Porto: Editora Porto, 2001.

HOBSBAWM, Eric. Introdução. In: HOBSBAWM, Eric; RANGER, Terence (Org.). A invenção das tradições. 6. ed. São Paulo: Paz e Terra, 2008.

. A produção em massa de tradições: Europa, 1879 a 1914. In: HOBSBAWM, Eric; RANGER, Terence (Org.). A invenção das tradições. 6. ed. São Paulo: Paz e Terra, 2008a.

KALlL, Renan Bernardi. Ensaio sobre o ensino jurídico no Brasil. Revista Jus Navigandi Doutrina e Peças, 2012. Disponível em: http://www. jus.com. br. Acesso em: 27 fev. 2013.

LEITE, Carlinda (Org.). Sentidos da pedagogia no ensino superior. Porto: CllE/Livpsic, 2010.

Questões do currículo no ensino universitário: o que distingue a organização e o desenvolvimento do currículo deste nível de ensino? In: LEITE, Carlinda; PACHECO, José 
○nsino jurídico em contexto universitário português: tradições curriculares em debate

Augusto; MOREIRA, Antonio Flávio Barbosa, MOURAZ, Ana (Org.). Políticas, fundamentos e práticas do currículo. Porto: Porto Editora, 2011.

LEITE, Maria Cecília Lorea. Pedagogia universitária e Ciências Sociais Aplicadas: elementos para uma reflexão. In: FRANCO, Maria Estela Dal Pai; KRAHE, Elizabeth Diefenthaeler (Org.). Pedagogia universitária e áreas de conhecimento. Porto Alegre: EDIPUCRS, 2007.

PACHECO, José Augusto. Estudos curriculares: para a compreensão crítica da educação. Porto: Editora Porto, 2005.

PINAR, William. O que é a teoria do currículo. Porto: Porto Editora, 2007.

PORTUGAL. Decreto-Lei n. ${ }^{\circ}$ 42, de 22 de fevereiro de 2005. Institui os princípios reguladores dos instrumentos para a criação do espaço europeu de ensino superior. Diário da República, Portugal. Disponível em: http://www.dges.mctes.pt. Acesso em: 23 jan. 2013.

Decreto-Lei n. ${ }^{\circ}$ 74, de 24 de março de 2006. Aprova o regime jurídico dos graus e diplomas do ensino superior. Diário da República, Portugal. Disponível em: http://www. dges.mctes.pt. Acesso em: 23 jan. 2013.

Decreto-Lei n. ${ }^{\circ}$ 107, de 25 de junho de 2008. Institui os princípios reguladores dos instrumentos para a criação do espaço europeu de ensino superior. Diário da República,

40 Portugal. Disponível em: http://www.dges.mctes.pt. Acesso em: 23 jan. 2013.

ROBERTSON, Susan. O processo de Bolonha da Europa tornar-se global: modelo, mercado, mobilidade, força intelectual ou estratégia para construção do estado? Revista Brasileira de Educação, Rio de Janeiro, v. 14, n. 42, p. 407-422, set./dez. 2009.

ROLDÃO, Maria do Céu. Diferenciação curricular revisitada. Porto: Porto Editora, 2003.

SACRISTÁN, José Gimeno. O currículo em ação: os resultados como legitimação do currículo. In: SACRISTÁN, José Gimeno (Org.). Saberes e incertezas sobre o currículo. Tradução Alexandre Salvaterra. Porto Alegre: Penso, 2013.

SANTOS, Lucíola Licínio de Castro Paixão. Entrevista com o Prof. António Nóvoa. Educação \& Sociedade, Campinas, v.33, n. 119, p. 633-645, abr./jun. 2012.

SANTOS, Boaventura de Sousa. Análise interdisciplinar do Direito no século XXI. In: SEMINÁRIO FORMAÇÃO DE MAGISTRADOS PARA UMA SOCIEDADE MAIS JUSTA E MAIS DEMOCRÁTICA, 2013, Coimbra. Anais... Coimbra: Universidade de Coimbra/Centro de Estudos Sociais/Laboratório Associado à Universidade de Coimbra. Disponível em: http: // www.tjto.jus.br/esmat. Acesso em: 27 fev. 2013. 
TEODORO, António. Bolonha e a reforma universitária: dos riscos potenciais às possibilidades de mudança. In: SERRALHEIRO, José Paulo (Org.). O processo de Bolonha e a formação dos educadores e professores portugueses. Porto: Profedições, 2005.

VILLAS BOAS, Marco. Análise interdisciplinar do Direito no século XXI. In: SEMINÁRIO FORMAÇÃO DE MAGISTRADOS PARA UMA SOCIEDADE MAIS JUSTA E MAIS DEMOCRÁTICA, 2013, Coimbra. Anais... Coimbra: Universidade de Coimbra/Centro de Estudos Sociais/Laboratório Associado à Universidade de Coimbra. Disponível em: http:// www.tjto.jus.br/esmat. Acesso em: 27 fev. 2013.

ZABALZA, Miguel. Competencias docentes del professora do universitário: calidad y desarrollo profesional. 2. ed. Madrid: NARCEA Ediciones, 2011.

Profa. Dra. Cely do Socorro Costa Nunes

Universidade de Lisboa Instituto de Educação Unidade de Investigação e Desenvolvimento em Educação e Formação | UIDEF

Grupo de Pesquisa Política Educacional Área de Especialidade | Avaliação em Educação

E-mail | csnunes@ie.ulisboa.pt

Recebido 5 maio 2014 Aceito 22 dez. 2014 